\title{
Climate and habitat loss interactively restructure trait composition and covariance across a human-modified landscape
}

\author{
Meghna Krishnadas ${ }^{1}$ \\ ${ }^{1}$ Centre for Cellular and Molecular Biology CSIR
}

September 26, 2021

\begin{abstract}
Species traits influence their response to environmental conditions and the match between phenotypes and environment mediates spatial changes in species composition. These trait-environment linkages can be disrupted in human-modified landscapes. Human land-use creates habitat fragments where dispersal limitation or edge effects can exclude species that may otherwise suit a given macro-scale environment. Furthermore, stressful micro-environments in fragments may limit viable trait combinations resulting in stronger trait covariance compared to contiguous forest, especially in harsher macroenvironments. In a wet tropical forest landscape in the Western Ghats Biodiversity Hotspot of peninsular India, I compared fragments with adjacent contiguous forest for signatures of trait-mediated assembly of tree communities along macroenvironmental gradients. Using four key plant traits-seed size, specific leaf area (SLA), wood density, and maximum height-I evaluated changes in trait-mediated abundances and trait covariance across environmental gradients. Trait-mediated abundances primarily changed along the elevation gradient in contiguous forest, smaller-seeded, shorter, thinner-leaved species increased at higher elevations. In fragments, higher SLA species increased in more seasonal climate and decreased with higher precipitation, and larger seeds decreased at warmer sites. However, traits only weakly predicted abundances and only contiguous forests experienced significant compositional change via traits, driven by trait syndromes varying along a composite environmental gradient defined by elevation, water deficit, and soil $\mathrm{C}: \mathrm{N}$ ratio. Covariance of seed size and maximum height along gradients of precipitation and temperature revealed divergent constraints on viable phenotypes in fragments and contiguous forest. Notably, local biotic conditions (functional diversity) had stronger effects than environment in explaining trait covariance. Overall, the results imply that trait syndromes and trait covariance, rather than single traits, determine the phenotypes best suited to different macroenvironmental conditions and should inform management or restoration goals in fragments.
\end{abstract}

\section{Introduction}

Environment plays a key role in shaping community assembly (Kraft et al., 2015). Across an environmental gradient, species performance relates to their functional traits that mediate the ability to withstand different environmental conditions (Adler et al., 2013; Paine et al., 2011; Poorter et al., 2008; Sonnier et al., 2010). Trait-environment linkages influence compositional change across space and also shape community responses to anthropogenic change (Bernard-Verdier et al., 2012; Cornwell and Ackerly, 2009; Harrison and LaForgia, 2019; Méndez-Toribio et al., 2020; Poorter et al., 2019; Venail et al., 2015). In human-modified landscapes, remnant habitat exist as fragments embedded within a matrix of other land-uses (Barlow et al., 2007; Melo et al., 2013). Fragments experience edge effects that alter the microclimate (De Frenne et al., 2019, 2015; Zellweger et al., 2020) and forest-climate feedbacks that can enhance local climatic stress (Arroyo-Rodríguez et al., 2017; Laurance, 2004). Both processes can decouple the how different traits mediate community composition across macro-scale environmental gradients in fragments compared to contiguous forest (Fernandes Neto et al., 2019; Krishnadas et al., 2018b; Lebrija-Trejos et al., 2010; Poorter et al., 2019; Zirbel and Brudvig, 2020).

Trait-environment linkages can vary between fragments and contiguous forest because of changes in the 
relative importance of different stressors. For trees, consider wood density and specific leaf area (SLA). Denser wood and lower SLA correlate with greater shade-tolerance (Poorter et al., 2008; Wright et al., 2010). In contiguous forest, tree species with denser wood or lower SLA increase in wetter sites where shade limits species performance. However, greater light availability in fragments could increase abundances of species with lighter wood and/or higher SLA in wetter sites, which would decouple the macro-scale linkages between traits and water availability. Alternatively, because denser wood and lower SLA also correlate with dry-tolerance, they may be favored where climatic water deficit increases across the contiguous forest (Muscarella et al., 2016; O'Brien et al., 2017; Sterck et al., 2006). Warmer, drier local conditions in fragments (Asbjornsen et al., 2004) may favor dry-tolerant traits even in wetter sites. However, if dry microclimates are more deleterious in drier climates, fragments may show tighter the macro-scale linkage between water deficit and lower SLA and/or higher wood density. Instead of individual traits, environmental filters may select for multi-trait phenotypes (Umaña and Swenson, 2018), or assembly may be a response to a composite suite of environmental variables (Shen et al., 2019).

Environmental gradients also shape community assembly via constraints on trait combinations, reflected in trait covariance (Dwyer and Laughlin, 2017). Environmental stress can curtail viable trait combinations or select for specific phenotypes among locally co-occurring species, resulting in stronger covariance at more stressful sites (Dwyer and Laughlin, 2017; Umaña and Swenson, 2018). The sign of covariance also matters to recognize the phenotypes being favored. Positive covariance indicates selection for more extreme trait combinations (e.g., large seeded and dense wooded or large seeded and tall) as may happen if multiple stressors impose coordination across a suite of traits. Negative covariance may imply opposing selective pressures on traits, e.g., higher light availability supports smaller-seeded species but concomitant effects of dry conditions select for species shorter stature or thicker leaves (Muscarella et al., 2016; Tyree, 2003).

In fragments, limited arrival of larger-seeded species and warmer, drier microenvironments can constrain viable combinations of seed size and SLA, height or wood density. Trait covariance could therefore be tighter in fragments compared to contiguous forests, especially where macroclimatic stress also increases. Alternatively, greater heterogeneity of microenvironments within fragments could support more phenotypes than contiguous forest, resulting in a weaker influence of the macroenvironment on trait covariance. For instance, heterogeneous light levels within fragments may allow a wider range of viable SLA or wood density values for the same seed size, whereas more uniformly shaded conditions in contiguous forests restrict trait combinations. Finally, trait covariance could reflect the diversity of the trait space shaped by environmental gradients or local biotic interactions. An increase in the functional diversity of individual traits, i.e., wider occupancy of available niche space, could increase the number of possible phenotypes arising from trait combinations.

Here, I examined how trait-environment linkages and constraints on trait combinations varied between fragments and contiguous forests across macroenvironmental gradients in a human-modified wet tropical landscape in peninsular India. Specifically, I asked:

Do fragmented and contiguous forests differ in trait-mediated species distributions across macroenvironmental gradients?

In contiguous forest, I expected that traits associated with shade-tolerance (denser wood and lower SLA) would increase in wetter sites where there is strong competition for light. Greater light availability in fragments would favor smaller-seeded, lighter-wooded species on average, but larger seeded and denser wooded species would increase in fragments located in warmer, drier conditions. Drier climate in fragments would favor shorter species (Méndez-Toribio et al., 2020). Across contiguous forest however, uniformly shaded conditions may buffer the effects of drier climates allowing similar height profiles in relation to climatic dryness (Arroyo-Rodríguez et al., 2017; Davis et al., 2019; De Frenne et al., 2019).

Do contiguous forests and fragments differ in whether the environment selects for individual traits or multitrait phenotypes (i.e., trait syndromes) and does this influence composition along environmental gradients?

If selection along environmental gradients operates via individual traits, trait-environment correlations will 
be stronger for individual traits than multi-trait phenotypes in both contiguous forest and fragments (Butterfield and Suding, 2013; Krishnadas et al., 2018b). Alternatively, successful phenotypes may be determined by a combination of traits. Species with trait values associated with resource-conservative strategies would be expected to increase in more stressful conditions such as warmer, drier climates. If small-scale abiotic conditions in fragments modulate or override the effects of broad-scale environmental gradients, then landscape-level trait-environment linkages seen in contiguous forests will change for fragments.

Does the environment constrain trait combinations in fragments vs. contiguous forest? Or, does trait covariance correlate with the overall trait space occupied by constituent species?

In contiguous forest, I expected stronger trait covariance as sites became drier and warmer. I expected fragments to show stronger correlations between trait covariance and climate gradients as forest loss would reduce the buffering of climatic stress and allow less leeway for different phenotypes (Zellweger et al., 2020), i.e., stronger selection for specific phenotypes leading to tighter constraints on trait combinations. I also expected trait covariance to decrease with higher species richness, functional diversity, or variance of individual traits.

\section{Materials and Methods}

\section{Study area}

The study was conducted in the Western Ghats biodiversity hotspot of southern India. The landscape $\left(12.17^{\circ} \mathrm{N}, 75.80^{\circ} \mathrm{E}\right)$, located in Kodagu district of Karnataka state, is classified as mid-elevation evergreen forests (Pascal, 1986). Elevation spanned 650-1100 m ASL and mean annual precipitation ranged from ca. 2400-3800 mm across sites. The region has well-drained clayey and loamy type soils (Anonymous, 1998). The forests here were fragmented $c a .100$ years ago with the expansion of coffee plantations, paddy fields and human settlements. For the last 40 years, both contiguous and fragmented forests were legally protected against land-use change, extraction and hunting. Local communities also protect fragments from conversion due to their cultural value as sacred groves (Osuri and Sankaran, 2016b).

Data collection

Vegetation sampling: I obtained the data on tree communities from an online repository (Osuri and Sankaran, 2016a). The dataset comprised of 50 square plots of $30 \times 30 \mathrm{~m}-31$ plots at eight locations within contiguous forest and 19 plots in eight forest fragments. All plots were censused during Jan-Dec 2011. Sampled fragments ranged from 5-10 ha in size, chosen to avoid ongoing or recent disturbance or human-use. Vegetation plots were placed at least 50-m from fragment edges and 50-m apart from each other. The contiguous forest plots were located within a complex of structurally connected nature reserves adjacent to the fragments. Shade coffee plantations dominated the land-use in the human-modified matrix. For more details of the plot locations and placement, see Osuri and Sankaran (2016b). Species were identified using field keys, regional floras (Pascal and Ramesh 1997; Ramesh et al. 2007) and with input from experienced botanists. We excluded about $3 \%$ of individuals as could not be identified to genus or species because they had no leaves or the canopy was obscured by climbers.

Traits: I used four key functional traits of plants-seed size, wood density, specific leaf area (SLA) and maximum height-that were available in the supplementary information included with Osuri \& Sankaran (2016b). Trait data was collected between November 2011 and January 2013 following standard protocols (Cornelissen et al. 2003) from trees within or adjacent to the vegetation plots. The data collection methods have been detailed in Osuri and Sankaran (2016b). Here, I briefly repeat the main aspects.

For SLA, five mature, healthy, sun-exposed canopy leaves were collected per tree at the end of the wet season (October-December) for 358 trees comprising 79 species. Leaf areas were estimated using the Black Spot Leaf Area Calculator (Varma and Osuri, 2013), after which leaves were oven-dried at $60^{\circ} \mathrm{C}$ for $72 \mathrm{~h}$ to obtain dry weights. Wood density was estimated by dividing dry weight by fresh volume of trunk wood cores collected with an increment borer, for 352 trees representing 74 species. Thirty-six species for which adequate primary data could not be collected, wood density was also collated from secondary sources (Chave et al., 2009). Seed size was quantified as the length of the primary seed axis, for 34 species (1879 seeds in 
total). Additionally, seed size data were obtained from two other mid-elevation evergreen forests in the Western Ghats (D. Mudappa, unpublished data). For species without primary measurements, seed lengths were collated from published secondary sources (Matthew 1983; Saldanha \& Ramesh 1984; Ramesh et al. 2007). Maximum heights for each species were obtained in the field and from secondary sources (Matthew 1983; Saldanha \& Ramesh 1984; Ramesh et al. 2007).

Environmental data: I used mean Climatological Water Deficit (Chave et al., 2014) to quantify site-level variation in seasonal water stress (Condit et al., 2013; Vicente-Serrano et al., 2013). CWD, measured in $\mathrm{mm} /$ year, is always a negative number since it is the difference between rainfall and evapotranspiration during dry months only, and more negative values indicate greater water deficit. Data were downloaded from the source cited in Chave et al. (2014; http://chave.ups-tlse.fr/pantropical_allometry.htm\#CWD). I also characterized site-level climate aridity with Annual Evapotranspiration (AET) data, available at a spatial resolution of $1 \mathrm{~km}^{2}$, and can be downloaded from the CGIAR-CSI GeoPortal (https://cgiarcsi.community). I also used data from WorldClim, collated per $1 \mathrm{~km}^{2}$, to characterize gradients in precipitation and temperature across the study region (Hijmans et al., 2005). I used mean annual precipitation, mean precipitation of the driest quarter, mean precipitation of the warmest quarter, mean annual temperature, mean temperature of the warmest quarter, and the mean temperature of the driest quarter.

Statistical analysis

Trait-environment interactions: I used generalized linear mixed-effects models to assess differences between contiguous forest and fragments in the interactions of traits with different environmental variables in explaining species abundances (Brown et al., 2014; Jamil et al., 2013). As detailed in Jamil et al. (2013), the response variable was the abundance of each species per site, including zeros, modeled using a negative binomial error structure. Site-to-site variation in abundance was modeled in relation to a three-way interaction between traits, climate, and habitat type (fragment/contiguous). Plots (nested within sites) and species were included as random intercepts. A zero-inflation component was included to account for the fact that most species were absent in many plots. Zero-inflation was modeled for the intercept and as a function of the trait in each model. Zero-inflated models performed better than models without zero-inflation (based on AIC). I also decomposed the four traits using Principal Components Analysis to get composite phenotypes using the first three axes that explained $\sim 91 \%$ of the interspecific variation in trait values (Figure S1). I used 'varimax' rotation to maximize the loadings per axis. The first axis loaded for maximum height (0.94) and seed size (0.66), second axis for wood density (0.99), and third axis for SLA (0.96) and partly seed size (-0.55).

I used Principal Components Analysis to decompose the temperature and precipitation variables from WorldClim into two composite axes that together explained $~ 90 \%$ of variation in climate across sites (Figure S2). Climate axis 1 explained $63.2 \%$ variation and primarily captured the precipitation gradient, with positive values corresponding with greater precipitation. Climate axis 2 represented a temperature gradient; more positive values indicated warmer sites. Because environmental variables were correlated (Figure S3), I used the Variance Inflation Factor to remove collinear variables (Fox and Weisberg, 2019). Variables with VIF $>4$ were removed from the model. Separate models were run per trait. In all models, Climate axis 1, Climate axis 2, CWD, and soil C:N ratio were the final environmental predictors retained. In addition, because elevation was strongly correlated with CWD, Climate axis 1, and Climate axis 2, and had been previously seen as a key predictor of compositional change in this landscape, I implemented models with elevation as the sole predictor for changes in trait-mediated abundances.

RLQ and fourth-corner analyses: The second question was to assess trait-mediated changes in species composition across environmental gradients. This may occur via a) individual traits changing along individual environmental gradients, b) individual traits changing along combination of environmental conditions, or c) trait combinations (functional syndromes) responding to a combination of environmental conditions. To tease apart these possibilities, I used the RLQ and Fourth-Corner methods. RLQ identifies the links between environmental gradients and trait syndromes as reflected by species abundances, and Fourth-Corner analysis performs formal statistical tests of hypotheses regarding trait-environment linkages (Dray et al., 2014; PeresNeto, Dray, \& ter Braak, 2017). For this procedure, $\mathbf{R}$ is the matrix of environmental variables by sample 
sites, $\mathbf{Q}$ has species $\mathrm{x}$ trait data, and $\mathbf{L}$ is a site $\mathbf{x}$ species matrix of abundances or occurrences. The RLQ outputs decompose correlations in the data along orthogonal axes for a global measure of trait-environment linkages (Dray et al., 2014). The Fourth-Corner analysis evaluates multiple bivariate correlations between traits and environmental variables, using permutation tests on the RLQ outputs to assess the relationship between (a) individual functional traits and single or combined environmental gradients (RLQ environment scores), and (b) environmental variables and functional syndromes (RLQ traits scores) (Dray et al., 2014).

Following the procedure detailed by Dray et al. (2014), I first analyzed the $\mathbf{L}$-table using correspondence analysis (CA), followed by standardized principal components analysis (PCA) of the $\mathbf{R}$ and $\mathbf{Q}$-tables. Then, I used the RLQ method to evaluate the proportions of variation in the environmental ordination and the trait ordination from the RLQ axes. I tested the global significance of trait-environment relationships (RLQ axes) and bivariate correlations between traits and environmental variables with the "randtest.rlq" and "fourthcorner.rlq" functions, respectively. To control false positive error rates in multiple comparisons, I used the Benjamini-Hochberg false discovery rate (BH-FDR) procedure (Benjamini \& Hochberg, 1995) with 9,999 permutations to estimate P-values.

I ran separate RLQ analyses for fragments and contiguous forest to compare their trait-environment linkages. SLA and seed size were log transformed and all traits scaled prior to analysis. All calculations and graphs were made using package "ade4" in R version 4.0.1 (R Core Team, 2016). For this analysis, I included all environmental variables together since the multivariate analysis accounted for collinearity.

Trait covariance: To assess how environmental gradients influenced trait covariance, for each plot I calculated the covariance of each pairwise combination of the four traits using methods and $\mathrm{R}$ codes in Dwyer and Laughlin (2017). Trait covariance may change in direct response to environmental conditions or because biotic characteristics of sites, such as the diversity of species or functions, vary with environment. As sitelevel biotic characteristics, I used rarefied species richness, two metrics of multi-trait functional diversity (functional dispersion and functional evenness) and the abundance-weighted variance of each trait in the pair of traits used to assess trait covariance. Rarefied richness provides a measure of species diversity after accounting for differences in stem density. Functional dispersion quantifies the divergence of species in the trait space and incorporates changes in both functional richness and functional divergence (Mason et al., 2013; Mouchet et al., 2010). Functional evenness reveals the uniformity of trait distribution among constituent species. Variance of individual traits provides a measure of the functional space represented by each trait.

The relationships between biotic characteristics the environment can differ between fragments and contiguous forest. So, I first examined how each biotic characteristic varied in relation to an interaction of habitat type (fragment and contiguous forest) and environmental gradients. For this, I used simple linear models. Preliminary analysis with mixed-effects models showed minimal effects of site-level variance on model coefficients and variance explained, and higher AIC than linear models. None of the biotic characteristics varied between fragment and contiguous forest (Table S1) or with the environmental variables considered here (Tables S2 S4), so I used them along with environmental variables as predictors for trait covariance.

I used linear models to model plot-level covariance of each trait pair as a function of the interactions of habitat type (fragment/contiguous) with environmental variables and biotic characteristics of a plot. As with trait-abundance associations, I used VIF to remove correlated predictors and reduce collinearity. Four climate variables were consistently retained in all models: CWD, Climate axis 1, Climate axis 2, and soil $\mathrm{C}: \mathrm{N}$ ratio. Because elevation was strongly correlated with the first three of these variables, I repeated all models with elevation as the sole predictor for changes in site-level trait covariance.

\section{Results}

Trait- environment interactions: As expected, the four traits differed in their interaction with environmental variables to predict species distributions across the landscape (Krishnadas et al., 2018b), and traitenvironment interactions differed between fragments and contiguous forest (Table 1). Interestingly, models with elevation alone explained similar extents of variation in trait-mediated abundances as models with multiple environmental predictors (Table S1). In contiguous forest, higher elevations had lower abundances 
of species with higher SLA and greater maximum height, wood density and seed size, with seed size showing the strongest interaction with elevation. Only seed size-elevation interaction differed between fragments and contiguous forest; fragments had larger-seeded species at higher elevations (Figure 1).

In contiguous forest, lower water deficit (less negative CWD) corresponded with increased abundance of shorter statured and smaller-seeded species, and these relationships did not change for fragments (Table 1). Although SLA did not interact with any environmental gradient to shape abundances in contiguous forest, in fragments, higher SLA species increased as water deficit decreased (lower CWD) and declined with higher values of climate axis 1, i.e., wetter, cooler sites. Larger values of climate axis 1 also associated with larger-seeded species in contiguous forest, with no change in fragments. However, in fragments, largerseeded species declined with larger values of climate axis 2 (warmer sites) even though climate axis 2 did not influence trait-mediated abundances in contiguous forest. Trends remained similar with PCA axes, which explained similar variation in the data as individual traits (Table S1). Overall, trait-environment interactions at most explained $\sim 16 \%$ of the variation in species abundances, with maximum height being the trait that best explained change in species abundance across climate gradients (Table 1). Except for the model with maximum height, random effects explained more variation than fixed effects (Table 1, see conditional vs. marginal $\mathrm{R}^{2}$ ).

RLQ and fourth-corner analysis: Only contiguous forest showed significant trait-environment linkages in driving compositional change-the first RLQ axis explained $76.4 \%$ and second axis $21.1 \%$ of the crossvariance in traits and environment (Figure 2a). In fragments, $88 \%$ of the cross-variance between traits and environment was explained by the model (Figure 2b), but results were not statistically significant after accounting for multiple comparisons. In contiguous forest, fourth-corner analysis revealed that trait-mediated structuring of communities across environmental gradients occurred along multiple pathways (Figure 3a). Trait axis R1 showed significant positive correlation with environmental axis Q1, which represented a trait syndrome defined by a combination of wood density, SLA and seed size. Correspondingly, sites defined by a combination of greater elevation, higher C:N ratio, and less negative CWD had significantly higher SLA and seed sizes (Figure $3 \mathrm{~b}$ ). Elevation showed a positive correlation with the syndrome represented by trait axis 1 representing phenotypes of smaller seeded, shorter, and thicker-leaved species (Figure 3c). Fourth corner analysis for fragments revealed no significant correlations between trait axes and broad-scale environmental axes, when corrected for multiple comparisons. Moreover, no individual trait showed significant correlation with any individual environmental variable in either fragments or contiguous forest.

Trait covariance: All coefficients for the models of trait covariance are provided in Table S3. In fragments, WD-SS covariance showed a significant negative correlation with CWD, while this relationship was not statistically significant in contiguous forest (Figure 4a). SS-MH covariance decreased in wetter, warmer sites (higher values of climate axes 1 and 2), and increased with greater C:N ratio in contiguous forest (Figure 4b, 4c). In fragments, the relationship with both climate axes reversed. SS-MH covariance increased with greater variance in seed size in contiguous forest, with no significant change in this relationship within fragments. In contiguous forest, SLA-WD covariance decreased with declining climatic water deficit and increasing soil CN ratio.

SLA-WD covariance had positive and negative correlations respectively with multi-trait functional dispersion (FDis) and variance in SLA, both correlations changed sign in fragments (Figure 5, a-c). SLA-MH covariance did not correlate with any predictor. SLA-SS covariance decreased with larger variance in SLA in contiguous forest, and this remained similar in fragments (Figure 5d). WD-MH covariance in contiguous forest was only correlated with biotic variables: decreasing with greater FDis and increasing with greater variance of both traits (Figure 5, g-i). Only the correlation with $\mathrm{MH}$ variance changed in fragments, becoming strongly negative. Unlike for trait-mediated abundances, elevation alone did not explain trait covariance as well as multiple climate variables together (Table S4).

\section{Discussion}

Across a human-modified landscape consisting of forest fragments adjacent to contiguous forests, trait- 
mediated changes in species abundances revealed that similar environmental gradients act differently in fragments compared to contiguous forests in the same landscape. Compositional change in contiguous forest occurred via multiple environmental factors acting simultaneously to select for combinations of traits. Notably, fragments had no discernible trait-environment linkages that mediated compositional change across environmental gradients. Environmental influence on trait covariance suggests than constraints on trait combinations may be important criteria to manage and restore fragments for composition and function.

\section{Trait-environment linkages in fragments vs. contiguous forest}

Elevation played a key role in driving trait-mediated abundances in contiguous forest. Higher elevations had species with thicker leaves, shorter stature, less dense wood and smaller seeds. The increase in thicker-leaved species was not in response to higher elevations being wetter and colder. Similarly, the increase in shortstatured species at higher elevations was not due to more rainfall because taller-statured species increased in sites with more rain (Climate axis 1), consistent with expectations that drier climates favor shorter species (Méndez-Toribio et al., 2020). Notably though, water deficit had a stronger influence than Climate axis 1 on height, with water-limited sites (more negative CWD) having taller species. While this pattern runs contrary to expectation, it may explain the increase in shorter-statured species at higher elevations where water deficit decreased, albeit moderately.

Given these opposing patterns and unclear trends in SLA and height, observed trait-abundance associations may have resulted from stronger selection for another trait in contiguous forest. Seed size was the strongest driver of changes across elevation, and increase in smaller-seeded species at higher elevations would also lead to shorter, thicker-leaved species (PCA1, Fig. S1). Seed size-elevation linkages may have resulted from a decline in larger-seeded species at sites with lower water deficit. In fragments however, neither CWD nor climate axis 1 explained seed size mediated changes in abundance. Additionally, factors unmeasured here could drive compositional change, e.g., greater wind speed at higher elevation may strongly favor shorterstatured species (Umaña and Swenson, 2018), that in this landscape were associated with smaller seeds (Osuri and Sankaran, 2016b). While traits do seem to explain compositional change along the elevational gradient (Krishnadas and Osuri, 2020), the mechanisms clearly need evaluation (Loranger et al., 2018).

Compared to contiguous forest, the seed size-elevation linkage changed in fragments. Larger-seeded species increased at higher elevations, perhaps driven by larger-seeded species being more abundant at cooler sites. Species with higher SLA increased as water deficit decreased, suggesting that sites with lower water stress supported resource-acquisitive strategies (Méndez-Toribio et al., 2020). The relationship with water stress is consistent with patterns across larger-scale gradients of CWD in the Western Ghats, where low SLA species were more likely to occur in water-stressed sites (Krishnadas et al., 2021). Surprisingly though, higher precipitation correlated with an increase in low SLA species, albeit CWD being the stronger driver. This pattern may be attributed to greater shade in sites with higher rainfall; lower SLA values correlate with better shade tolerance (Reich, 2014; Wright et al., 2010). Overall though, trait-environment interactions alone (i.e., without random effects) explained at most $\sim 16 \%$ variation in species abundances across the landscape as a whole.

\section{Multi-trait phenotypes drove compositional change}

The weak influence of any single trait on abundances indicates that assembly occurred along multiple environmental axes, sometimes in opposing directions. Corroborating this, no combination of a single trait with a single environmental gradient explained net compositional change in either fragments or contiguous forest. However, in contiguous forest, trait syndromes shaped compositional variation along a composite environmental gradient defined by elevation, soil fertility and climatic water deficit (RLQ axis 1). Sites with higher elevation, soil fertility and lower water deficit had species with lower SLA and smaller seeds, the latter being consistent with trait-abundance associations (see above). These results suggest the need to examine the role of trait coordination in determining species' responses to multiple stressors (Díaz et al., 2015; Shen et al., 2019).

Elevation was the only standalone gradient that significantly explained trait-mediated compositional change, 
but only in contiguous forest. Read together with trait-abundance associations, compositional change across the elevation gradient was driven by multiple environmental factors acting in concert (Figure S2). In contrast with contiguous forest, trait-environment linkages did not mediate compositional change across fragments. Thus, changes in the abundances of species with different traits along climate gradients did not translate into changes in community-level trait composition in fragments. In particular, fragments being located at higher elevations on average than contiguous forest may have dampened the effects of elevation on trait-mediated changes in composition. Trait-environment linkages may also be disrupted if fragments experience more flux than contiguous forests in species' recruitment and survival (Collins et al., 2017; Laurance, 2002). Stochastic population dynamics or impact of local microclimate on species performance could obscure or override the role of larger-scale trait-environment linkages that otherwise mediate community assembly.

\section{Trait covariance in fragments}

SS-MH covariance had nearly all positive values, indicating that at all sites larger seeds were associated with taller stature. In contiguous forest, wetter (Climate axis 1) and warmer sites (Climate axis 2) had lower SS$\mathrm{MH}$ covariance, indicating more flexible combinations of stature and seed size. The smaller range of SS-MH phenotypes at cooler sites perhaps reflects the stress of lower temperatures at higher elevations in contiguous forest. In fragments by contrast, warmer sites had strong positive covariance of SS-MH, i.e., taller stature for a given seed size. Keeping in mind that larger-seeded species declined at warmer sites in fragments (Table 1 ), covariance patterns suggest smaller-seeded but taller species do well in warmer sites. This phenotype is consistent with long-lived pioneers (Rüger et al., 2018) and may reflect the fact that despite increased light availability in fragments, loss of canopy cover did not favor obligate heliophiles.

Notably, functional diversity explained variation in trait covariance better than climate variables, even though the different aspects of functional diversity did not vary between habitat types or along climate gradients. Changes in covariances of SLA-WD and WD-MH with trait variances showed that a larger trait space, especially of wood density, supported very different phenotypic combinations within fragments compared to contiguous forest. The causes, however, cannot be discerned from this study. Biotic interactions, e.g., interand intraspecific neighborhood interactions through natural enemies, can mediate site-to-site variation in functional diversity (Lasky et al., 2014; Muscarella et al., 2018, 2016). Whether neighborhood interactions differ between fragments and contiguous forests remains poorly explored (Krishnadas et al., 2018a). Local microclimate, unmeasured here, also affect functional diversity directly or indirectly (Butterfield and Suding, 2013; Krishnadas et al., 2018b; Muscarella et al., 2016). The drivers of relationships between phenotypic constraints and functional diversity merit deeper exploration in human-modified ecosystems.

\section{Implications for management}

In this landscape, decline in larger-seeded species in fragments compared to contiguous forest was attributed to dispersal limitation (Osuri and Sankaran, 2016b). Results here show that larger-seeded species primarily declined at lower elevations in fragments, likely driven by warmer conditions. At warmer, low elevation fragments however, larger seeded species had taller stature than at cooler, high elevation sites, suggesting the need to restore low elevation fragments with the shorter-statured larger-seeded species, i.e., mid-canopy shade-tolerant species. More seasonal sites (negative CWD) supported phenotypes of taller stature and larger seeds in both contiguous forest and fragments. Since larger-seeded species stored more carbon due to their taller stature here (Osuri and Sankaran, 2016b), to increase above-ground biomass, restore taller, larger-seeded species at fragments located in more seasonal climate. Although this study showed which phenotypes are lost from fragments situated in different climatic conditions, planning for restoration will require identifying the main impediments faced by different phenotypes to persist in fragments (e.g., dispersal or unsuitable environments).

\section{Conclusion}

Habitat loss altered the effects of macroclimate on community assembly, calling attention to the scaledependence of trait-mediated composition in human-modified landscapes. Relatively weak ability of individual traits to predict abundance and opposing axes of trait-mediated assembly suggest the need to examine 
trait-coordination for multiple stressors (Craine et al., 2012; Shen et al., 2019). Moreover, 'soft' traits measured here clearly do not provide sufficient insights into community-level responses to climate gradients (Li et al., 2015; Shipley et al., 2016). Measuring a wider suite of traits relevant to different stressors will help capture the full spectrum of functions that govern compositional change in human-modified forests (Maréchaux et al., 2019; Medeiros et al., 2019; Shipley et al., 2016). For example, no studies have yet correlated hydraulic traits to species performance in the warmer, drier microclimates near fragment edges. Shifts in the success of phenotypes with habitat loss could be due to edge effects that alter forest microclimates (Arroyo-Rodríguez et al., 2017; Davis et al., 2019): e.g., warmer, drier conditions near edges may amplify water stress during the dry season (Ewers and Banks-Leite, 2013). Examining how microclimate mediates the impacts of macroclimate on species performance would help predict compositional change in human-modified landscapes subject to a changing climate (De Frenne et al., 2019; Zellweger et al., 2020). Hierarchical, scale-dependent insights into trait-environment linkages will allow evidence-based restoration planning to achieve different targets such as community structure, diversity or ecosystem functioning (Laughlin, 2014; Laughlin et al., 2017).

\section{Acknowledgements}

I thank Osuri et al. for making their data publicly available.

\section{Funding}

This research did not receive any specific grant from funding agencies in the public, commercial, or not-forprofit sectors.

\section{Data accessibility statement}

The data used in this study can be publicly accessed from Dryad Digital Repository (https://doi.org/10.5061/dryad.7s7r1) and Supplementary Material in Osuri and Sankaran (2016b).

\section{References}

Adler, P.B., Fajardo, A., Kleinhesselink, A.R., Kraft, N.J.B., 2013. Trait-based tests of coexistence mechanisms. Ecol. Lett. 16, 1294-1306. https://doi.org/10.1111/ele.12157

Anonymous, 1998. Karnataka Soils. National Bureau of Soil Survey and Land Use Planning, Nagpur, India.

Arroyo-Rodríguez, V., Saldaña-Vázquez, R.A., Fahrig, L., Santos, B.A., 2017. Does forest fragmentation cause an increase in forest temperature? Ecol. Res. 32, 81-88. https://doi.org/10.1007/s11284-016-1411-6

Asbjornsen, H., Ashton, M.S., Vogt, D.J., Palacios, S., 2004. Effects of habitat fragmentation on the buffering capacity of edge environments in a seasonally dry tropical oak forest ecosystem in Oaxaca, Mexico. Agric. Ecosyst. Environ. 103, 481-495. https://doi.org/10.1016/j.agee.2003.11.008

Barlow, J., Gardner, T.A., Araujo, I.S., Avila-Pires, T.C., Bonaldo, A.B., Costa, J.E., Esposito, M.C., Ferreira, L. V., Hawes, J., Hernandez, M.I.M., Hoogmoed, M.S., Leite, R.N., Lo-Man-Hung, N.F., Malcolm, J.R., Martins, M.B., Mestre, L. a. M., Miranda-Santos, R., Nunes-Gutjahr, A.L., Overal, W.L., Parry, L., Peters, S.L., Ribeiro-Junior, M.A., da Silva, M.N.F., da Silva Motta, C., Peres, C.A., Ávila-Pires, T.C., Bonaldo, A.B., Costa, J.E., Esposito, M.C., Ferreira, L. V., Hawes, J., Hernandez, M.I.M., Hoogmoed, M.S., Leite, R.N., Lo-Man-Hung, N.F., Malcolm, J.R., Martins, M.B., Mestre, L. a. M., Miranda-Santos, R., NunesGutjahr, A.L., Overal, W.L., Parry, L., Peters, S.L., Ribeiro-Junior, M.A., Silva, M.N.F. da, Motta, C. da S., Peres, C.A., 2007. Quantifying the biodiversity value of tropical primary, secondary, and plantation forests. Proc. Natl. Acad. Sci. 104, 18555-18560. https://doi.org/10.1073/pnas.0703333104

Bernard-Verdier, M., Navas, M.L., Vellend, M., Violle, C., Fayolle, A., Garnier, E., 2012. Community assembly along a soil depth gradient: Contrasting patterns of plant trait convergence and divergence in a Mediterranean rangeland. J. Ecol. 100, 1422-1433. https://doi.org/10.1111/1365-2745.12003 
Brown, A.M., Warton, D.I., Andrew, N.R., Binns, M., Cassis, G., Gibb, H., 2014. The fourth-corner solution - using predictive models to understand how species traits interact with the environment. Methods Ecol. Evol. 5, 344-352. https://doi.org/10.1111/2041-210X.12163

Butterfield, B.J., Suding, K.N., 2013. Single-trait functional indices outperform multi-trait indices in linking environmental gradients and ecosystem services in a complex landscape. J. Ecol. 101, 9-17. https://doi.org/10.1111/1365-2745.12013

Chave, J., Coomes, D., Jansen, S., Lewis, S.L., Swenson, N.G., Zanne, A.E., 2009. Towards a worldwide wood economics spectrum. Ecol. Lett. 12, 351-366. https://doi.org/10.1111/j.1461-0248.2009.01285.x

Chave, J., Réjou-Méchain, M., Búrquez, A., Chidumayo, E., Colgan, M.S., Delitti, W.B.C., Duque, A., Eid, T., Fearnside, P.M., Goodman, R.C., Henry, M., Martínez-Yrízar, A., Mugasha, W.A., Muller-Landau, H.C., Mencuccini, M., Nelson, B.W., Ngomanda, A., Nogueira, E.M., Ortiz-Malavassi, E., Pélissier, R., Ploton, P., Ryan, C.M., Saldarriaga, J.G., Vieilledent, G., 2014. Improved allometric models to estimate the aboveground biomass of tropical trees. Glob. Chang. Biol. 20, 3177-3190. https://doi.org/10.1111/gcb.12629

Collins, C.D., Banks-Leite, C., Brudvig, L.A., Foster, B.L., Cook, W.M., Damschen, E.I., Andrade, A., Austin, M., Camargo, J.L., Driscoll, D.A., Holt, R.D., Laurance, W.F., Nicholls, A.O., Orrock, J.L., 2017. Fragmentation affects plant community composition over time. Ecography (Cop.). 40, 119-130. https://doi.org/10.1111/ecog.02607

Condit, R., Engelbrecht, B.M.J., Pino, D., Perez, R., Turner, B.L., 2013. Species distributions in response to individual soil nutrients and seasonal drought across a community of tropical trees. Proc. Natl. Acad. Sci. 110, 5064-5068. https://doi.org/10.1073/pnas.1218042110

Cornwell, W.K., Ackerly, D.D., 2009. Community assembly and shifts in plant trait distributions across an environmental gradient in coastal California. Ecol. Monogr. 79, 109-126. https://doi.org/10.1890/07-1134.1

Craine, J.M., Engelbrecht, B.M.J., Lusk, C.H., McDowell, N.G., Poorter, H., 2012. Resource limitation, tolerance, and the future of ecological plant classification. Front. Plant Sci. 3, 1-10. https://doi.org/10.3389/fpls.2012.00246

Davis, K.T., Dobrowski, S.Z., Holden, Z.A., Higuera, P.E., Abatzoglou, J.T., 2019. Microclimatic buffering in forests of the future: the role of local water balance. Ecography (Cop.). 42, 1-11. https://doi.org/10.1111/ecog.03836

De Frenne, P., Rodríguez-Sánchez, F., De Schrijver, A., Coomes, D.A., Hermy, M., Vangansbeke, P., Verheyen, K., 2015. Light accelerates plant responses to warming. Nat. Plants 1, 7-9. https://doi.org/10.1038/nplants.2015.110

De Frenne, P., Zellweger, F., Rodríguez-Sánchez, F., Scheffers, B.R., Hylander, K., Luoto, M., Vellend, M., Verheyen, K., Lenoir, J., 2019. Global buffering of temperatures under forest canopies. Nat. Ecol. Evol. 3, 744-749. https://doi.org/10.1038/s41559-019-0842-1

Díaz, S., Kattge, J., Cornelissen, J.H.C., Wright, I.J., Lavorel, S., Dray, S., Reu, B., Kleyer, M., Wirth, C., Colin Prentice, I., Garnier, E., Bönisch, G., Westoby, M., Poorter, H., Reich, P.B., Moles, A.T., Dickie, J., Gillison, A.N., Zanne, A.E., Chave, J., Joseph Wright, S., Sheremet'ev, S.N., Jactel, H., Baraloto, C., Cerabolini, B., Pierce, S., Shipley, B., Kirkup, D., Casanoves, F., Joswig, J.S., Günther, A., Falczuk, V., Rüger, N., Mahecha, M.D., Gorné, L.D., 2015. The global spectrum of plant form and function. Nature 529, 167-171. https://doi.org/10.1038/nature16489

Dwyer, J.M., Laughlin, D.C., 2017. Constraints on trait combinations explain climatic drivers of biodiversity: the importance of trait covariance in community assembly. Ecol. Lett. 20, 872-882. https://doi.org/10.1111/ele.12781

Ewers, R.M., Banks-Leite, C., 2013. Fragmentation Impairs the Microclimate Buffering Effect of Tropical Forests. PLoS One 8, e58093. https://doi.org/10.1371/journal.pone.0058093 
Fernandes Neto, J.G., Costa, F.R.C., Williamson, G.B., Mesquita, R.C.G., 2019. Alternative functional trajectories along succession after different land uses in central Amazonia, Journal of Applied Ecology. https://doi.org/10.1111/1365-2664.13484

Fox, J., Weisberg, S., 2019. An R Companion to Applied Regression Third Edition, SAGE Publications, Inc.

Harrison, S., LaForgia, M., 2019. Seedling traits predict drought-induced mortality linked to diversity loss. Proc. Natl. Acad. Sci. U. S. A. 116, 5576-5581. https://doi.org/10.1073/pnas.1818543116

Hijmans, R.J., Cameron, S.E., Parra, J.L., Jones, P.G., Jarvis, A., 2005. Very high resolution interpolated climate surfaces for global land areas. Int. J. Climatol. 25, 1965-1978. https://doi.org/10.1002/joc.1276

Jamil, T., Ozinga, W.A., Kleyer, M., Ter Braak, C.J.F., 2013. Selecting traits that explain speciesenvironment relationships: A generalized linear mixed model approach. J. Veg. Sci. 24, 988-1000. https://doi.org/10.1111/j.1654-1103.2012.12036.x

Kraft, N.J.B., Adler, P.B., Godoy, O., James, E.C., Fuller, S., Levine, J.M., 2015. Community assembly, coexistence and the environmental filtering metaphor. Funct. Ecol. 29, 592-599. https://doi.org/10.1111/13652435.12345

Krishnadas, M., Bagchi, R., Sridhara, S., Comita, L.S., 2018a. Weaker plant-enemy interactions decrease tree seedling diversity with edge-effects in a fragmented tropical forest. Nat. Commun. 9, 4523. https://doi.org/10.1038/s41467-018-06997-2

Krishnadas, M., Beckman, N.G., Zuluaga, J.C.P., Zhu, Y., Whitacre, J., Wenzel, J.W., Queenborough, S.A., Comita, L.S., 2018b. Environment and past land use together predict functional diversity in a temperate forest. Ecol. Appl. 28, 2142-2152. https://doi.org/10.1002/eap.1802

Krishnadas, M., Osuri, A.M., 2020. Environment shapes the spatial organization of tree diversity in fragmented forests across a human-modified landscape. Ecol. Appl. https://doi.org/10.1002/eap.2244

Krishnadas, M., Sankaran, M., Page, N., Joshi, J., Machado, S., Nataraj, N., Chengappa, S.K., Kumar, V., Kumar, A., Krishnamani, R., 2021. Seasonal drought regulates species distributions and assembly of tree communities across a tropical wet forest region. Glob. Ecol. Biogeogr. geb.13350. https://doi.org/10.1111/geb.13350

Lasky, J.R., Uriarte, M., Boukili, V.K., Chazdon, R.L., 2014. Trait-mediated assembly processes predict successional changes in community diversity of tropical forests. Proc. Natl. Acad. Sci. U. S. A. 111, 5616-21. https://doi.org/10.1073/pnas.1319342111

Laughlin, D.C., 2014. Applying trait-based models to achieve functional targets for theory-driven ecological restoration. Ecol. Lett. 17, 771-784. https://doi.org/10.1111/ele.12288

Laughlin, D.C., Strahan, R.T., Moore, M.M., Fule, P.Z., Huffman, D.W., Covington, W.W., 2017. The hierarchy of predictability in ecological restoration: are vegetation structure and functional diversity more predictable than community composition? J. Appl. Ecol. 54, 1058-1069. https://doi.org/10.1111/13652664.12935

Laurance, W., 2002. Hyperdynamism in fragmented habitats. J. Veg. Sci. 13, 595. https://doi.org/10.1658/1100-9233(2002)013[0595:HIFH]2.0.CO;2

Laurance, W.F., 2004. Forest-climate interactions in fragmented tropical landscapes. Philos. Trans. R. Soc. Lond. B. Biol. Sci. 359, 345-52. https://doi.org/10.1098/rstb.2003.1430

Lebrija-Trejos, E., Perez-garcia, E.A., Meave, J.A., Bongers, F., Poorter, L., 2010. Functional traits and environmental filtering drive community assembly in a species-rich tropical system. Ecology 91, 386-398. https://doi.org/10.1890/08-1449.1 
Li, R., Zhu, S., Chen, H.Y.H., John, R., Zhou, G., Zhang, D., Zhang, Q., Ye, Q., 2015. Are functional traits a good predictor of global change impacts on tree species abundance dynamics in a subtropical forest? Ecol. Lett. 18, 1181-1189. https://doi.org/10.1111/ele.12497

Loranger, J., Munoz, F., Shipley, B., Violle, C., 2018. What makes trait-abundance relationships when both environmental filtering and stochastic neutral dynamics are at play? Oikos 127, 1735-1745. https://doi.org/10.1111/oik.05398

Marechaux, I., Saint-Andre, L., Bartlett, M.K., Sack, L., Chave, J., 2019. Leaf drought tolerance cannot be inferred from classic leaf traits in a tropical rainforest. J. Ecol. 1-16. https://doi.org/10.1111/13652745.13321

Mason, N.W.H.H., De Bello, F., Mouillot, D., Pavoine, S., Dray, S., 2013. A guide for using functional diversity indices to reveal changes in assembly processes along ecological gradients. J. Veg. Sci. 24, 794-806. https://doi.org/10.1111/jvs.12013

Medeiros, C.D., Scoffoni, C., John, G.P., Bartlett, M.K., Inman-Narahari, F., Ostertag, R., Cordell, S., Giardina, C., Sack, L., 2019. An extensive suite of functional traits distinguishes Hawaiian wet and dry forests and enables prediction of species vital rates. Funct. Ecol. 33, 712-734. https://doi.org/10.1111/13652435.13229

Melo, F.P.L., Arroyo-Rodriguez, V., Fahrig, L., Martinez-Ramos, M., Tabarelli, M., $2013 . \quad$ On the hope for biodiversity-friendly tropical landscapes. Trends Ecol. Evol. 28, 461-468. https://doi.org/10.1016/j.tree.2013.01.001

Mendez-Toribio, M., Ibarra-Manriquez, G., Paz, H., Lebrija-Trejos, E., 2020. Atmospheric and soil drought risks combined shape community assembly of trees in a Tropical Dry Forest, Journal of Ecology. https://doi.org/10.1111/1365-2745.13355

Mouchet, M.A., Villeger, S., Mason, N.W.H., Mouillot, D., 2010. Functional diversity measures: an overview of their redundancy and their ability to discriminate community assembly rules. Funct. Ecol. 24, 867-876. https://doi.org/10.1111/j.1365-2435.2010.01695.x

Muscarella, R., Messier, J., Condit, R., Hubbell, S.P., Svenning, J.C., 2018. Effects of biotic interactions on tropical tree performance depend on abiotic conditions. Ecology 99, 2740-2750. https://doi.org/10.1002/ecy.2537

Muscarella, R., Uriarte, M., Erickson, D.L., Swenson, N.G., Kress, W.J., Zimmerman, J.K., 2016. Variation of tropical forest assembly processes across regional environmental gradients. Perspect. Plant Ecol. Evol. Syst. 23, 52-62. https://doi.org/10.1016/j.ppees.2016.09.007

O'Brien, M.J., Engelbrecht, B.M.J., Joswig, J., Pereyra, G., Schuldt, B., Jansen, S., Kattge, J., Landhausser, S.M., Levick, S.R., Preisler, Y., Vaananen, P., Macinnis-Ng, C., 2017. A synthesis of tree functional traits related to drought-induced mortality in forests across climatic zones. J. Appl. Ecol. 54, 1669-1686. https://doi.org/10.1111/1365-2664.12874

Osuri, A.M., Sankaran, M., 2016a. Data from: Seed size predicts community composition and carbon storage potential of tree communities in rainforest fragments in India's Western Ghats., Dryad Digital Repository. https://doi.org/10.5061/dryad.7s7r1

Osuri, A.M., Sankaran, M., 2016b. Seed size predicts community composition and carbon storage potential of tree communities in rain forest fragments in India's Western Ghats. J. Appl. Ecol. 837-845. https://doi.org/10.1111/1365-2664.12626

Paine, C.E.T., Baraloto, C., Chave, J., Herault, B., 2011. Functional traits of individual trees reveal ecological constraints on community assembly in tropical rain forests. Oikos 120, 720-727. https://doi.org/10.1111/j.1600-0706.2010.19110.x 
Pascal, J.P., 1986. Explanatory Booklet on the Forest Map of South India. Sheets: Belgaum-DharwarPanaji, Shimoga, Mercara-Mysore.. Inst. Francais Pondichery.

Poorter, L., Rozendaal, D.M.A., Bongers, F., de Almeida-Cortez, J.S., Almeyda Zambrano, A.M., Alvarez, F.S., Andrade, J.L., Villa, L.F.A., Balvanera, P., Becknell, J.M., Bentos, T. V., Bhaskar, R., Boukili, V., Brancalion, P.H.S., Broadbent, E.N., Cesar, R.G., Chave, J., Chazdon, R.L., Colletta, G.D., Craven, D., de Jong, B.H.J., Denslow, J.S., Dent, D.H., DeWalt, S.J., Garcia, E.D., Dupuy, J.M., Duran, S.M., Espirito Santo, M.M., Fandino, M.C., Fernandes, G.W., Finegan, B., Moser, V.G., Hall, J.S., Hernandez-Stefanoni, J.L., Jakovac, C.C., Junqueira, A.B., Kennard, D., Lebrija-Trejos, E., Letcher, S.G., Lohbeck, M., Lopez, O.R., Marin-Spiotta, E., Martinez-Ramos, M., Martins, S. V., Massoca, P.E.S., Meave, J.A., Mesquita, R., Mora, F., de Souza Moreno, V., Muller, S.C., Munoz, R., Muscarella, R., de Oliveira Neto, S.N., Nunes, Y.R.F., Ochoa-Gaona, S., Paz, H., Pena-Claros, M., Piotto, D., Ruiz, J., Sanaphre-Villanueva, L., SanchezAzofeifa, A., Schwartz, N.B., Steininger, M.K., Thomas, W.W., Toledo, M., Uriarte, M., Utrera, L.P., van Breugel, M., van der Sande, M.T., van der Wal, H., Veloso, M.D.M., Vester, H.F.M., Vieira, I.C.G., Villa, P.M., Williamson, G.B., Wright, S.J., Zanini, K.J., Zimmerman, J.K., Westoby, M., 2019. Wet and dry tropical forests show opposite successional pathways in wood density but converge over time. Nat. Ecol. Evol. 3, 928-934. https://doi.org/10.1038/s41559-019-0882-6

Poorter, L., Wright, S.J., Paz, H., Ackerly, D.D., Condit, R., Ibarra-Manriquez, G., Harms, K.E., Licona, J.C., Martinez-Ramos, M., Mazer, S.J., Muller-Landau, H.C., Pena-Claros, M., Webb, C.O., Wright, I.J., Pena-Claros, M., Webb, C.O., Wright, I.J., Peña-Claros, M., Webb, C.O., Wright, I.J., 2008. Are functional traits good predictors of demographic rates? Evidence from five neotropical forests. Ecology 89, 1908-1920. https://doi.org/10.1890/07-0207.1

Reich, P.B., 2014. The world-wide 'fast-slow' plant economics spectrum: a traits manifesto. J. Ecol. 102, 275-301. https://doi.org/10.1111/1365-2745.12211

Rüger, N., Comita, L.S., Condit, R., Purves, D., Rosenbaum, B., Visser, M.D., Wright, S.., Wirth, C., 2018. Beyond the fast-slow continuum: demographic dimensions structuring a tropical tree community. Ecol. Lett. 21, 1075-1084. https://doi.org/10.1111/ele.12974

Shen, Y., Umaña, M.N., Li, W., Fang, M., Chen, Y., Lu, H., Yu, S., 2019. Coordination of leaf, stem and root traits in determining seedling mortality in a subtropical forest. For. Ecol. Manage. 446, 285-292. https://doi.org/10.1016/j.foreco.2019.05.032

Shipley, B., De Bello, F., Cornelissen, J.H.C., Lalibert??, E., Laughlin, D.C., Reich, P.B., 2016. Reinforcing loose foundation stones in trait-based plant ecology. Oecologia 180, 923-931. https://doi.org/10.1007/s00442016-3549-x

Sonnier, G., Shipley, B., Navas, M.-L., 2010. Quantifying relationships between traits and explicitly measured gradients of stress and disturbance in early successional plant communities. J. Veg. Sci. 21, 1014-1024. https://doi.org/10.1111/j.1654-1103.2010.01210.x

Sterck, F.J., Poorter, L., Schieving, F., 2006. Leaf traits determine the growth-survival trade-off across rain forest tree species. Am. Nat. 167, 758-65. https://doi.org/10.1086/503056

Tyree, M.T., 2003. Plant hydraulics: The ascent of water. Nature 423, 923-923. https://doi.org/10.1038/423923a

Umaña, M.N., Swenson, N.G., 2018. Does trait variation within broadly distributed species mirror patterns across species? A case study in Puerto Rico. Ecology 0, 1-11. https://doi.org/10.1002/ecy.2745

Varma, V., Osuri, A.M., 2013. Black Spot: A platform for automated and rapid estimation of leaf area from scanned images. Plant Ecol. 214, 1529-1534. https://doi.org/10.1007/s11258-013-0273-z

Venail, P., Gross, K., Oakley, T.H., Narwani, A., Allan, E., Flombaum, P., Isbell, F., Joshi, J., Reich, P.B., Tilman, D., van Ruijven, J., Cardinale, B.J., 2015. Species richness, but not phylogenetic diversity, influences 
community biomass production and temporal stability in a re-examination of 16 grassland biodiversity studies. Funct. Ecol. 29, 615-626. https://doi.org/10.1111/1365-2435.12432

Vicente-Serrano, S.M., Gouveia, C., Camarero, J.J., Beguería, S., Trigo, R., López-Moreno, J.I., AzorínMolina, C., Pasho, E., Lorenzo-Lacruz, J., Revuelto, J., Morán-Tejeda, E., Sanchez-Lorenzo, A., 2013. Response of vegetation to drought time-scales across global land biomes. Proc. Natl. Acad. Sci. U. S. A. 110, 52-57. https://doi.org/10.1073/pnas.1207068110

Wright, S.J., Kitajima, K., Kraft, N.J.B., Reich, P.B., Wright, I.J., Bunker, D.E., Condit, R., Dalling, J.W., Davies, S.J., Díaz, S., Engelbrecht, B.M.J., Harms, K.E., Hubbell, S.P., Marks, C.O., Ruiz-Jaen, M.C., Salvador, C.M., Zanne, A.E., 2010. Functional traits and the growth-mortality trade-off in tropical trees. Ecology 91, 3664-74. https://doi.org/10.1890/09-2335.1

Zellweger, F., De Frenne, P., Lenoir, J., Vangansbeke, P., Verheyen, K., Bernhardt-Römermann, M., Baeten, L., Hédl, R., Berki, I., Brunet, J., Van Calster, H., Chudomelová, M., Decocq, G., Dirnböck, T., Durak, T., Heinken, T., Jaroszewicz, B., Kopecký, M., Máliš, F., Macek, M., Malicki, M., Naaf, T., Nagel, T.A., Ortmann-Ajkai, A., Petř́k, P., Pielech, R., Reczyńska, K., Schmidt, W., Standovár, T., Świerkosz, K., Teleki, B., Vild, O., Wulf, M., Coomes, D., 2020. Forest microclimate dynamics drive plant responses to warming. Science (80-. ). 368, 772-775. https://doi.org/10.1126/science.aba6880

Zirbel, C.R., Brudvig, L.A., 2020. Trait-environment interactions affect plant establishment success during restoration. Ecology 101, 1-7. https://doi.org/10.1002/ecy.2971

\section{MANUSCRIPT TABLES \& FIGURES}

Table 1. Parameter estimates from models to assess how species relative abundances relate to three-way interactions of traits, environmental gradients and habitat type (fragment/contiguous forest). The analysis used linear mixed effects model with negative binomial errors and zero-inflation component, with random intercepts for sites and species.

\begin{tabular}{|c|c|c|c|c|}
\hline & SLA & Max height & Wood density & Seed size \\
\hline (Intercept) & $-0.41(0.48)$ & $-0.53(0.47)$ & $-0.78(0.54)$ & $-1.00(0.51)$ \\
\hline CWD & $0.09(0.07)$ & $0.11(0.07)$ & $0.06(0.08)$ & $0.03(0.07)$ \\
\hline Soil C:N ratio (SCN) & $0.10(0.05)$ & $0.09(0.05)$ & $0.10(0.05)$ & $0.11(0.05)$ \\
\hline Clim.1 & $-0.10(0.05)$ & $-0.08(0.05)$ & $-0.07(0.06)$ & $-0.05(0.05)$ \\
\hline Clim.2 & $-0.09(0.06)$ & $-0.1(0.06)$ & $-0.05(0.07)$ & $-0.02(0.07)$ \\
\hline Fragment & $2.11(1.34)$ & $2.44(1.28)$ & $2.38(1.44)$ & $2.34(1.31)$ \\
\hline Trait & $0.77(0.49)$ & $-0.12(0.46)$ & $1.07(0.43)$ & $1.55(0.54)$ \\
\hline Trait: Fragment & $-2.59(1.32)$ & $1.46(1.34)$ & $0.37(1.30)$ & $-2.29(1.39)$ \\
\hline CWD: Fragment & $-0.35(0.16)$ & $-0.47(0.15)$ & $-0.38(0.17)$ & $-0.38(0.15)$ \\
\hline Soil CN: Fragment & $-0.15(0.14)$ & $-0.19(0.13)$ & $-0.18(0.15)$ & $-0.18(0.14)$ \\
\hline Clim.1: Fragment & $0.20(0.09)$ & $0.25(0.09)$ & $0.21(0.10)$ & $0.24(0.09)$ \\
\hline Clim.2: Fragment & $-0.04(0.21)^{\prime}$ & $-0.08(0.20)$ & $-0.14(0.22)^{\prime}$ & $-0.22(0.20)$ \\
\hline CWD: Trait & $-0.02(0.07)$ & $-0.29(0.07)$ & $-0.11(0.07)$ & $-0.16(0.07)$ \\
\hline Soil CN: Trait & $-0.05(0.05)$ & $-0.05(0.04)$ & $-0.04(0.04)$ & $-0.14(0.05)$ \\
\hline Clim.1: Trait & $0.00(0.05)$ & $0.12(0.05)$ & $0.00(0.04)$ & $0.11(0.05)$ \\
\hline Clim.2: Trait & $0.08(0.06)$ & $0.14(0.05)$ & $0.09(0.06)$ & $0.12(0.07)$ \\
\hline CWD: Trait: Fragment & $0.32(0.16)$ & $0.05(0.16)$ & $0.15(0.16)$ & $0.11(0.17)$ \\
\hline Soil CN: Trait: Fragment & $0.25(0.14)$ & $-0.17(0.14)$ & $-0.06(0.13)$ & $0.18(0.14)$ \\
\hline Clim.1: Trait: Fragment & $-0.19(0.08)$ & $0.00(0.08)$ & $-0.12(0.09)$ & $0.02(0.09)$ \\
\hline Clim.2: Trait: Fragment & $-0.01(0.21)$ & $-0.33(0.20)$ & $-0.11(0.21)$ & $-0.66(0.23)$ \\
\hline Conditional $\mathrm{R}^{2}$ & 0.31 & 0.32 & 0.29 & 0.27 \\
\hline Marginal $\mathrm{R}^{2}$ & 0.06 & 0.16 & 0.09 & 0.07 \\
\hline Species effects & $0.92(0.96)$ & $0.94(0.97)$ & $0.65(0.81)$ & $0.85(0.92)$ \\
\hline
\end{tabular}




\begin{tabular}{lllll}
\hline & SLA & Max height & Wood density & Seed size \\
\hline Site effects & $0.02(0.13)$ & $0.01(0.09)$ & $0.02(0.13)$ & $0.01(0.08)$ \\
AIC & 8956 & 8961 & 8985 & 9003 \\
\hline
\end{tabular}

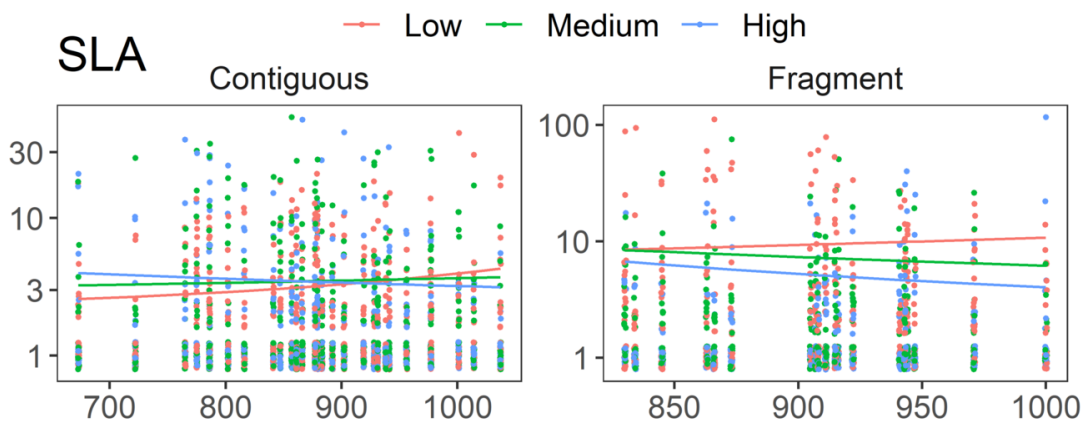

\section{Max. height}
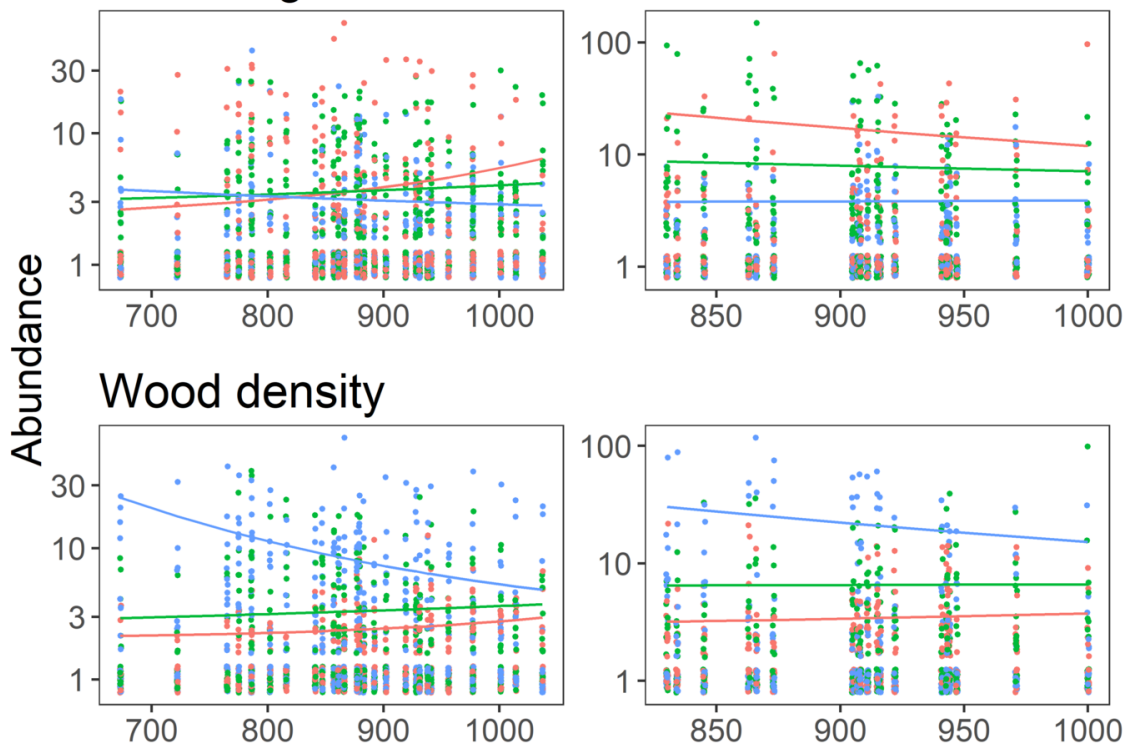

Seed size
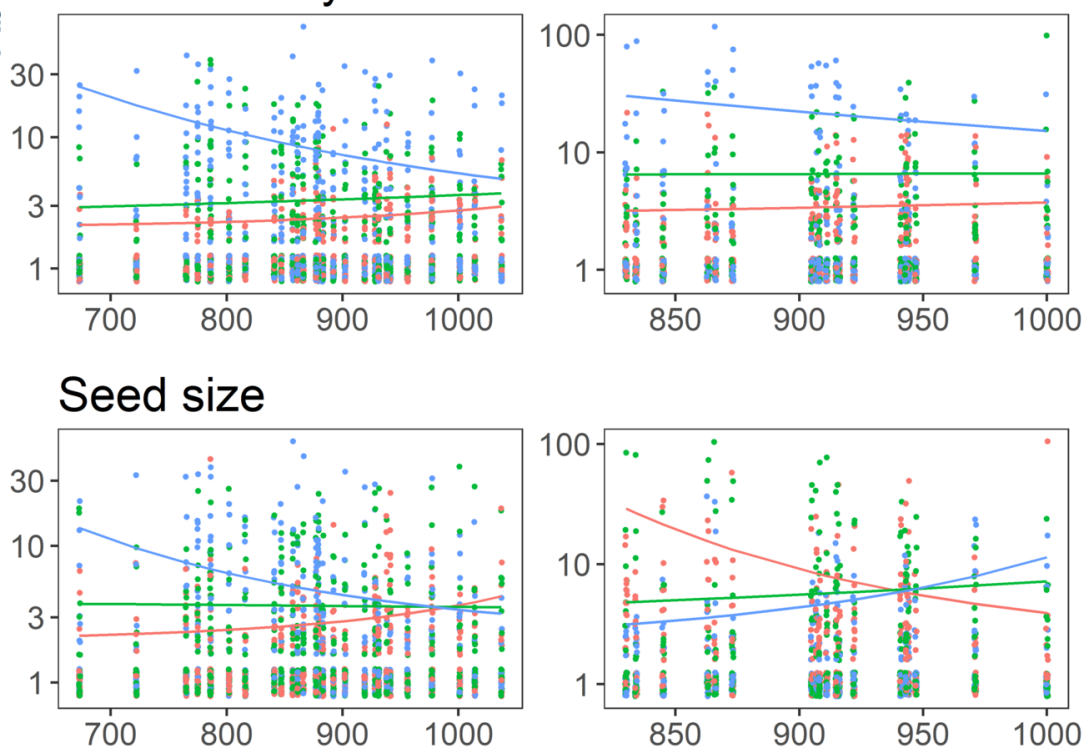

\section{Elevation}

Figure 1. Trait-abundance association with elevation. Changes in species abundances across elevational gradients in contiguous forest and fragments was modeled in relation to four functional traits. Generalized linear mixed-effects models with negative binomial errors and a zero-inflation component were 
used to model the relationships. Points indicate observed values and lines show predictions at $10^{\text {th }}$ (low), $50^{\text {th }}$ (medium) and $90^{\text {th }}$ (high) percentile of trait values. Note the log scale for $\mathrm{Y}$ axis and differing ranges for contiguous forest and fragments.

a. Contiguous

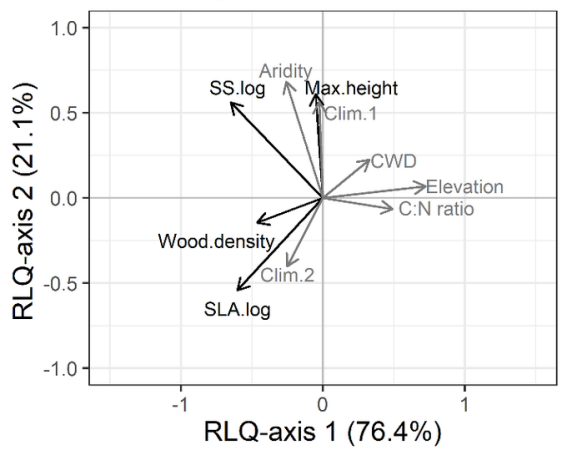

\section{b. Fragments}

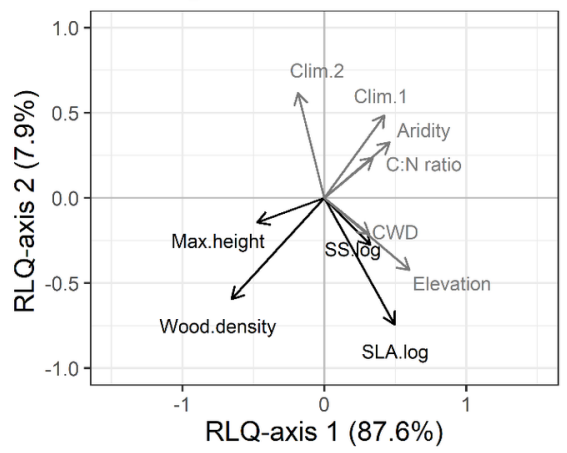

Figure 2. RLQ analysis of trait-environment linkages. For a) contiguous forests and b) forest fragments, correspondence analysis was used to assess links between species' traits, species composition and site-level environmental conditions. Both land-use types were situated adjacently in a human-modified landscape. Only contiguous forest showed significant relationships after correcting for multiple comparisons (see Figure 2).
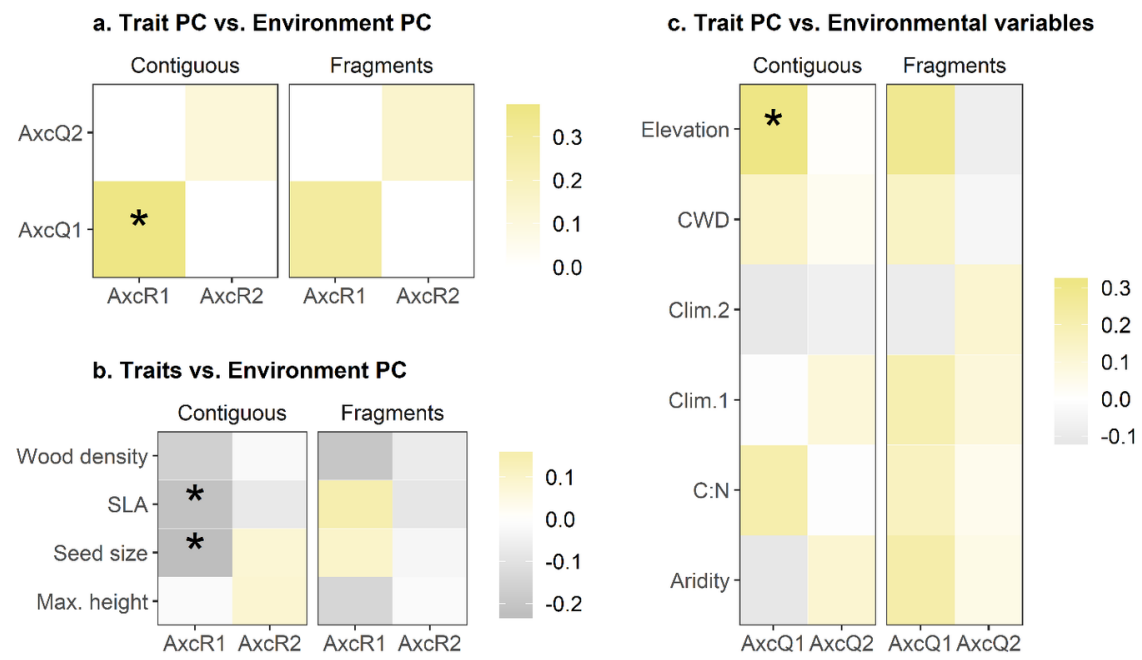

Figure 3. Fourth-corner analysis of RLQ outputs. Trait-mediated compositional change was assessed with respect to environmental gradients in fragments vs. contiguous forest, yielding relationships between a) composite trait axes and composite environmental gradients, b) individual traits and composite environmental gradients, and c) individual traits and individual environmental variables. Environment was characterized using elevation, climatic water deficit (CWD), climate axis 1 (Clim.1, precipitation gradient), climate axis 2 (Clim.2, temperature gradient), soil C:N ratio (C:N), and atmospheric aridity. P-values for significance 
of relationships was assessed using Benjamini-Hochberg correction for false positive results through 9999 random permutations of matrices.
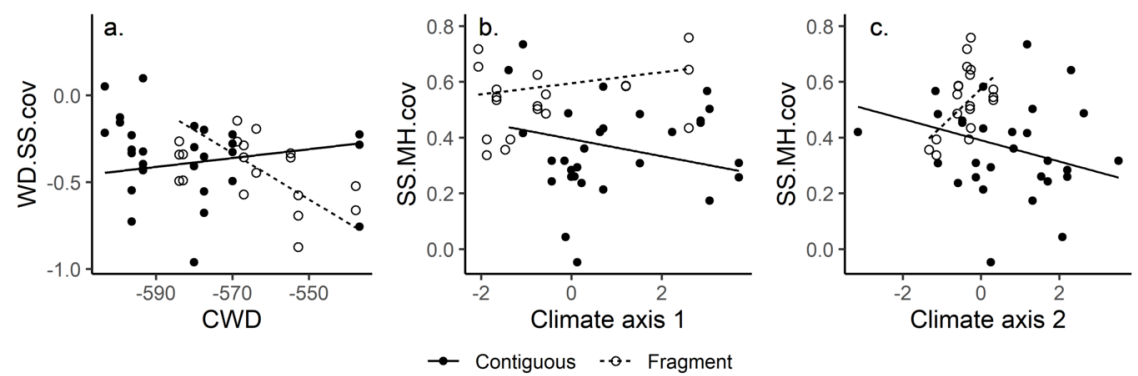

Figure 4. Trait covariance along environmental gradients.Environment across sites was characterized using Climatic Water Deficit, soil C:N ratio, and two composite climate axes derived from Principal Components Analysis of selected climate variables from WorldClim data (see Methods). Only relationships with significant trends are shown here. See Table S1 for all coefficient estimates. Prior to analysis, all predictors were standardized by subracting from their mean and dividing by one standard deviation and back transformed to the original scale.
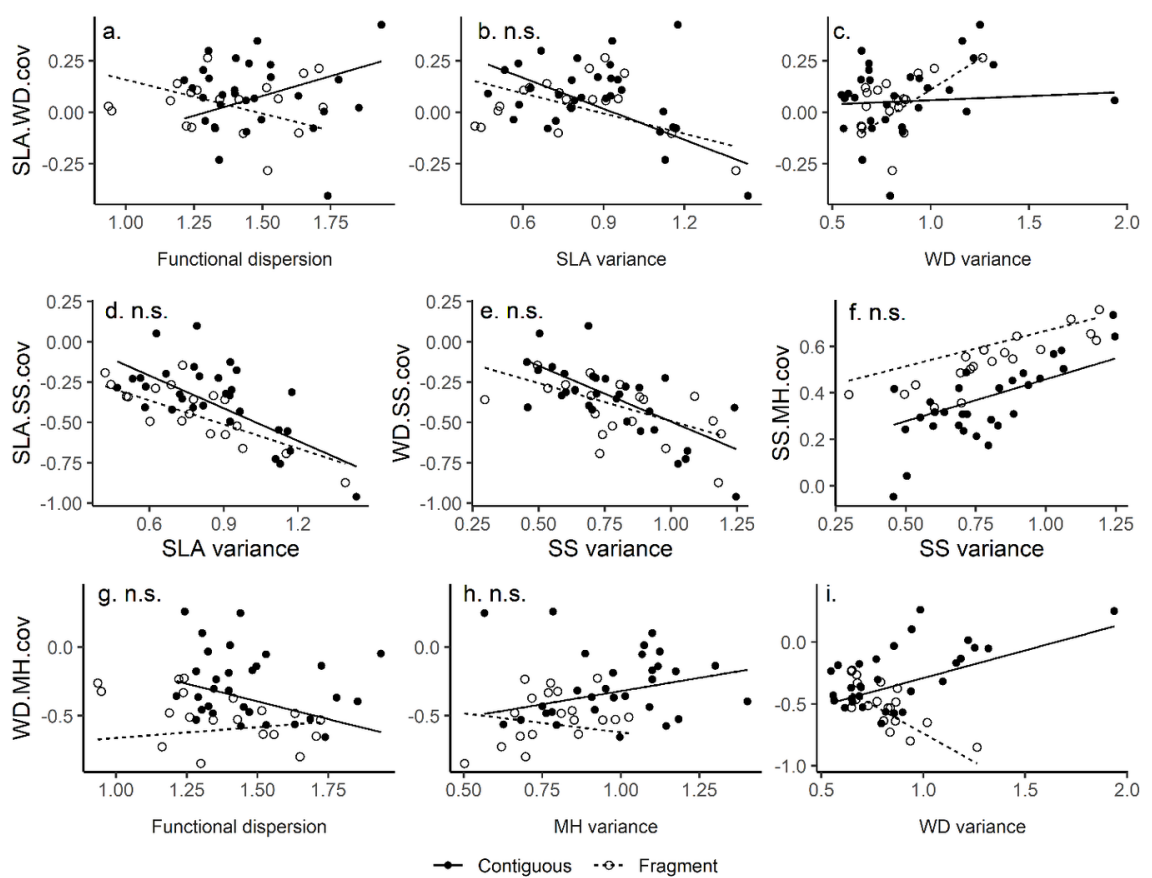

Figure 5. Trait covariance in relation to biotic factors. Biotic characteristics of each site were characterized by two metrics of multi-trait functional diversity (functional dispersion and functional evenness) and the variance of each trait in the pair of traits for covariance. Here, we present selected relationships that showed significant trends. See Table S1 for all coefficient estimates. In the panels, 'n.s.' indicates a nonsignificant interaction of biotic characteristics with habitat type (contiguous/fragment). Prior to analysis, all predictors were standardized by subracting from their mean and dividing by the standard deviation and have been back transformed here to the original scale. 


\section{SUPPLEMENTARY INFORMATION}

Table S1. Parameter estimates from models to assess how species abundances relate to three-way interaction of traits, elevation and habitat type (fragment/contiguous forest). The analysis used linear mixed effects model with negative binomial errors and zero-inflation component, with random intercepts for sites and species.

\begin{tabular}{|c|c|c|c|c|}
\hline & SLA & Max height & Wood density & Seed size \\
\hline (Intercept) & $0.39(0.15)$ & $0.22(0.15)$ & $0.09(0.14)$ & $-0.01(0.15)$ \\
\hline Elevation & $0.06(0.06)$ & $0.07(0.06)$ & $0.07(0.06)$ & $0.03(0.06)$ \\
\hline Fragment & $0.73(0.13)$ & $0.66(0.12)$ & $0.69(0.13)$ & $0.55(0.12)$ \\
\hline Trait & $0.28(0.14)$ & $-0.38(0.14)$ & $0.76(0.12)$ & $0.38(0.13)$ \\
\hline Elevation: Fragment & $-0.17(0.11)$ & $-0.30(0.11)$ & $-0.15(0.12)$ & $-0.60(0.11)$ \\
\hline Trait: Fragment & $-0.35(0.16)$ & $-0.47(0.15)$ & $-0.38(0.17)$ & $-0.38(0.15)$ \\
\hline Elevation: Trait & $-0.11(0.05)$ & $-0.15(0.04)$ & $-0.19(0.05)$ & $-0.25(0.06)$ \\
\hline Elevation: Trait: Fragment & $0.01(0.14)$ & $0.21(0.13)$ & $0.10(0.13)$ & $0.64(0.13)$ \\
\hline Conditional $\mathrm{R}^{2}$ & 0.31 & 0.31 & 0.32 & 0.27 \\
\hline Marginal $\mathrm{R}^{2}$ & 0.05 & 0.08 & 0.15 & 0.07 \\
\hline Species effects & $1.02(1.01)$ & $0.98(0.97)$ & $0.63(0.79)$ & $0.86(0.93)$ \\
\hline Site effects & $0.02(0.13)$ & $0.01(0.09)$ & $0.02(0.13)$ & $0.01(0.08)$ \\
\hline AIC & 8955 & 8965 & 8973 & 8991 \\
\hline
\end{tabular}

Table S2. Parameter estimates from models to assess how species abundances relate to three-way interactions of using PCA of traits, environmental gradients and habitat type (fragment/contiguous forest). The analysis used linear mixed effects model with negative binomial errors and zero-inflation component, with random intercepts for sites and species.

\begin{tabular}{llll}
\hline & PC1 & PC2 & PC3 \\
\hline (Intercept) & $-0.45(0.47)$ & $-0.84(0.54)$ & $-0.58(0.48)$ \\
CWD & $0.07(0.07)$ & $0.06(0.08)$ & $0.1(0.07)$ \\
Soil C:N ratio (SCN) & $0.09(0.05)$ & $0.11(0.05)$ & $0.11(0.05)$ \\
Clim.1 & $-0.08(0.05)$ & $-0.06(0.06)$ & $-0.1(0.05)$ \\
Clim.2 & $-0.06(0.06)$ & $-0.06(0.07)$ & $-0.1(0.07)$ \\
Fragment & $2.42(1.25)$ & $2.51(1.45)$ & $2.91(1.32)$ \\
Trait & $0.03(0.38)$ & $1.14(0.41)$ & $0.68(0.58)$ \\
Trait: Fragment & $0.9(0.93)$ & $-0.14(1.28)$ & $-0.66(1.8)$ \\
CWD: Fragment & $\mathbf{- 0 . 4 1 ( 0 . 1 5 )}$ & $\mathbf{- 0 . 4 ( 0 . 1 7 )}$ & $\mathbf{- 0 . 3 6 ( 0 . 1 6 )}$ \\
Soil CN: Fragment & $-0.18(0.13)$ & $-0.19(0.15)$ & $-0.25(0.14)$ \\
Clim.1: Fragment & $\mathbf{0 . 2 4}(\mathbf{0 . 0 8})$ & $\mathbf{0 . 2 1}(\mathbf{0 . 1})$ & $\mathbf{0 . 1 8}(\mathbf{0 . 0 9})$ \\
Clim.2: Fragment & $-0.12(0.2)$ & $-0.12(0.23)$ & $-0.07(0.21)$ \\
CWD: Trait & $-0.08(0.05)$ & $-0.09(0.07)$ & $\mathbf{- 0 . 3 1 ( 0 . 0 8 )}$ \\
Soil CN: Trait & $-0.02(0.04)$ & $-0.04(0.04)$ & $\mathbf{- 0 . 1 1}(\mathbf{0 . 0 6})$ \\
Clim.1: Trait & $0.05(0.03)$ & $0(0.04)$ & $\mathbf{0 . 1 9}(\mathbf{0 . 0 6})$ \\
Clim.2: Trait & $0.02(0.05)$ & $0.09(0.06)$ & $0.2(0.07)$ \\
CWD: Trait: Fragment & $-0.08(0.11)$ & $0.18(0.16)$ & $\mathbf{0 . 5 5}(\mathbf{0 . 2 2})$ \\
Soil CN: Trait: Fragment & $-0.1(0.1)$ & $-0.01(0.13)$ & $-0.02(0.19)$ \\
Clim.1: Trait: Fragment & $0.06(0.06)$ & $-0.11(0.09)$ & $\mathbf{- 0 . 3 9 ( 0 . 1 3 )}$ \\
Clim.2: Trait: Fragment & $-0.15(0.15)$ & $-0.15(0.21)$ & $-0.36(0.27)$ \\
Conditional R ${ }^{2}$ & 0.29 & 0.32 & 0.33 \\
Marginal R ${ }^{2}$ & 0.05 & 0.18 & 0.09
\end{tabular}




\begin{tabular}{llll}
\hline & PC1 & PC2 & PC3 \\
\hline Species effects & $1.00(1.00)$ & $0.63(0.79)$ & $1.01(1.03)$ \\
Site effects & $0.01(0.07)$ & $0.03(0.18)$ & $0.02(0.14)$ \\
AIC & 9011 & 8691 & 8972 \\
\hline
\end{tabular}

Table S3. Parameter estimates for models testing trait covariance in relation to environmental and biotic factors. Relationships were tested using linear mixed effects models with Gaussian errors. Plots nested within sites were included as random intercepts. Rare $=$ Rarefied richness, FDis $=$ Functional dispersion, FEve $=$ Functional evenness.

\begin{tabular}{|c|c|c|c|c|c|c|}
\hline & SLA-WD & SLA-MH & SLA-SS & WD-MH & WD-SS & SS-MH \\
\hline (Intercept) & $0.86(0.40)$ & $0.82(0.67)$ & $0.82(0.38)$ & $0.3(0.56)$ & $0.56(0.55)$ & $-0.88(0.29)$ \\
\hline CWD & $-0.08(0.03)$ & $-0.09(0.07)$ & $-0.07(0.04)$ & $-0.05(0.05)$ & $0.04(0.04)$ & $0.04(0.02)$ \\
\hline Soil C:N ratio $(\mathrm{SCN})$ & $-0.05(0.02)$ & $-0.06(0.03)$ & $-0.03(0.02)$ & $-0.03(0.03)$ & $0.01(0.03)$ & $0.03(0.01)$ \\
\hline Climate PC1 & $0.03(0.02)$ & $0.03(0.05)$ & $0.02(0.03)$ & $0.04(0.04)$ & $0.00(0.03)$ & $-0.03(0.01)$ \\
\hline Climate PC2 & $0.02(0.02)$ & $0.06(0.04)$ & $0.04(0.02)$ & $0.06(0.03)$ & $0.01(0.03)$ & $-0.04(0.01)$ \\
\hline Rare & $0.00(0.02)$ & $-0.03(0.03)$ & $-0.02(0.02)$ & $-0.04(0.03)$ & $0.00(0.03)$ & $0.00(0.01)$ \\
\hline FDis & $0.38(0.16)$ & $-0.19(0.24)$ & $0.16(0.14)$ & $-0.52(0.18)$ & $-0.21(0.2)$ & $0.29(0.10)$ \\
\hline FEve & $-0.75(0.48)$ & $0.04(0.8)$ & $-0.38(0.46)$ & $0.14(0.65)$ & $-0.44(0.61)$ & $0.40(0.32)$ \\
\hline Trait1.var & $-0.51(0.12)$ & $-0.26(0.18)$ & $-0.68(0.11)$ & $0.39(0.18)$ & $-0.69(0.18)$ & $0.36(0.10)$ \\
\hline Trait2.var & $0.04(0.09)$ & $0.2(0.22)$ & $-0.18(0.14)$ & $0.45(0.11)$ & $0.24(0.11)$ & $0.00(0.08)$ \\
\hline Fragment & $-1.28(0.64)$ & $-1.09(1.14)$ & $-0.42(0.63)$ & $0.71(1.08)$ & $0.07(0.9)$ & $2.01(0.51)$ \\
\hline CWD: Fragment & $0.15(0.08)$ & $0.02(0.17)$ & $-0.02(0.1)$ & $-0.1(0.11)$ & $-0.28(0.09)$ & $-0.08(0.05)$ \\
\hline SCN: Fragment & $0.09(0.06)$ & $0.04(0.09)$ & $0.00(0.05)$ & $-0.01(0.07)$ & $-0.05(0.08)$ & $-0.08(0.04)$ \\
\hline Clim.PC1: Fragment & $-0.03(0.04)$ & $-0.01(0.08)$ & $-0.01(0.05)$ & $-0.02(0.06)$ & $0.06(0.05)$ & $0.05(0.02)$ \\
\hline Clim.PC2: Fragment & $-0.09(0.08)$ & $-0.24(0.17)$ & $-0.17(0.09)$ & $-0.12(0.14)$ & $-0.17(0.11)$ & $0.17(0.06)$ \\
\hline Rare: Fragment & $0.04(0.03)$ & $-0.01(0.05)$ & $0.01(0.03)$ & $0.01(0.04)$ & $-0.01(0.04)$ & $0.00(0.02)$ \\
\hline FDis: Fragment & $-0.71(0.28)$ & $0.14(0.46)$ & $-0.12(0.26)$ & $0.68(0.38)$ & $0.12(0.37)$ & $-0.12(0.19)$ \\
\hline FEve: Fragment & $0.46(0.73)$ & $0.23(1.18)$ & $0.50(0.66)$ & $-0.22(0.96)$ & $0.52(0.94)$ & $-0.92(0.49)$ \\
\hline Trait1.var: Fragment & $0.17(0.24)$ & $-0.15(0.41)$ & $0.18(0.25)$ & $-0.67(0.55)$ & $0.22(0.27)$ & $-0.05(0.14)$ \\
\hline Trait2.var: Fragment & $0.56(0.22)$ & $0.46(0.5)$ & $-0.14(0.21)$ & $-1.37(0.42)$ & $-0.23(0.29)$ & $-0.21(0.20)$ \\
\hline Pseudo $\mathrm{R}^{2}$ & 0.57 & 0.51 & 0.75 & 0.67 & 0.61 & 0.84 \\
\hline
\end{tabular}




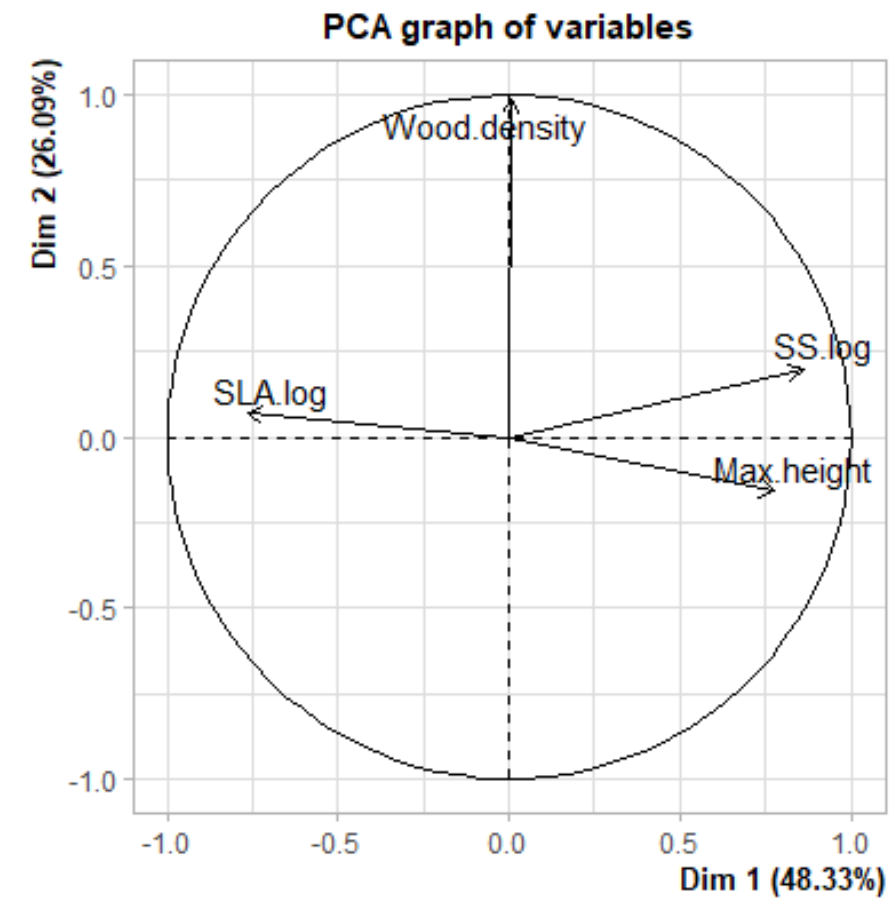

Figure S1. Principal Components Analysis of the four traits used. 


\section{PCA graph of variables}

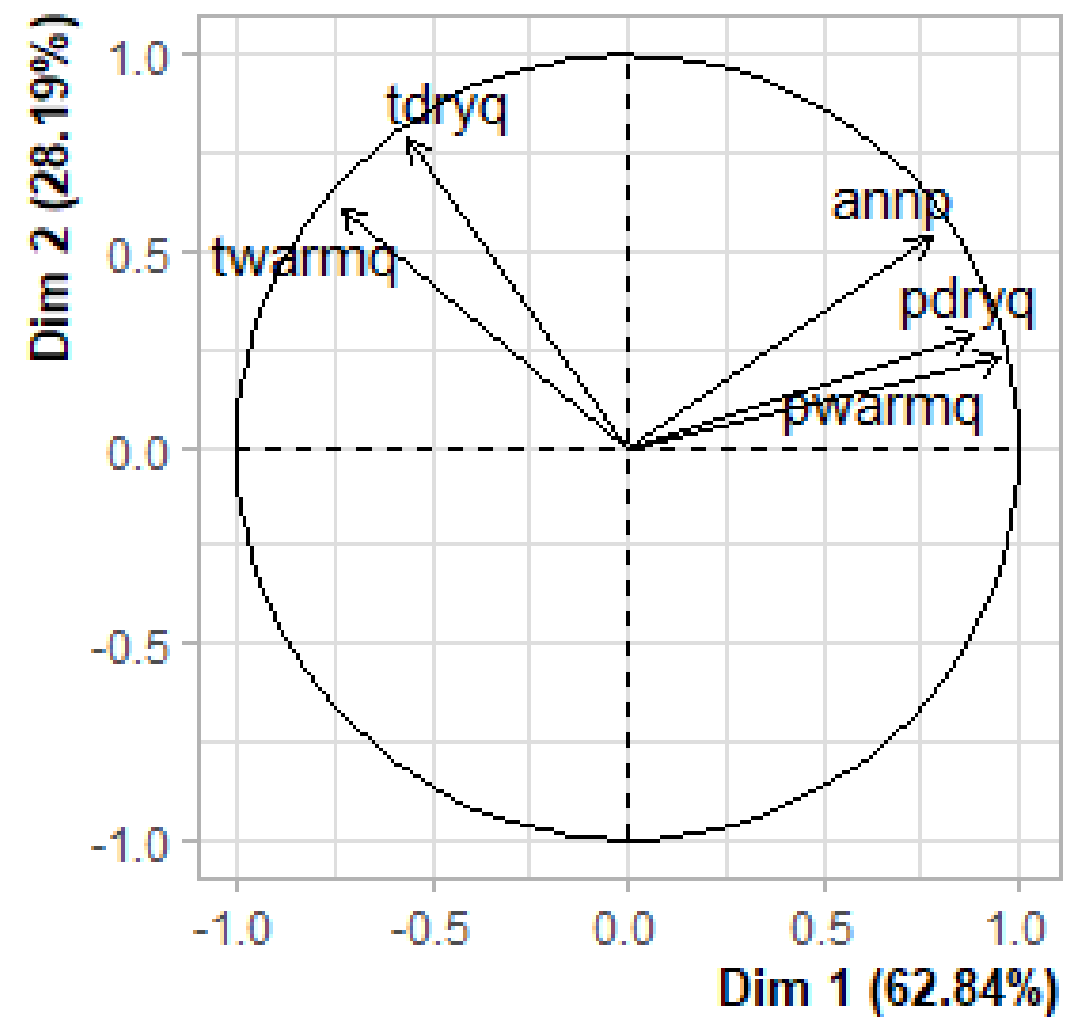

Figure S2. Principal Component Analysis (PCA) of precipitation and temperature variables from WorldClim. Five variables were chosen to represent composite climate axes: mean annual precipitation (annp), precipitation of driest quarter (pdryq), precipitation of warmest quarter (pwarmq), temperature of driest quarter (tdryq), temperature of warmest quarter (twarmq).

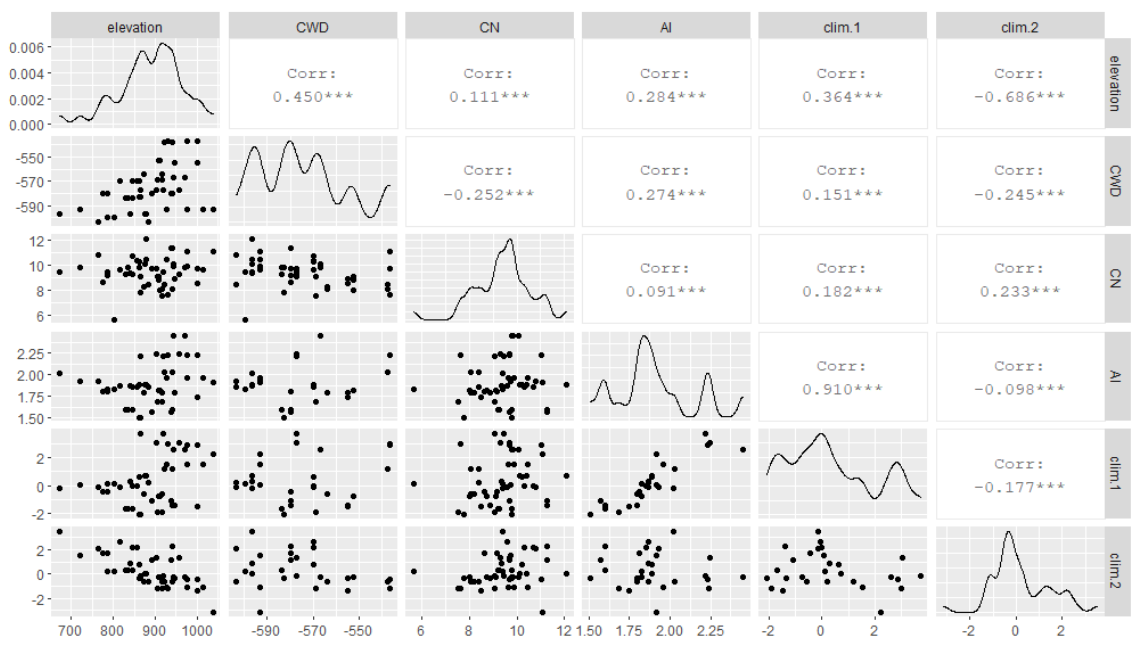

Figure S3. Pairwise correlations among environmental variables across the entire landscape. CWD = 
climatic water deficit, $\mathrm{CN}=$ soil $\mathrm{C}: \mathrm{N}$ ratio, $\mathrm{AI}=$ aridity index, $\operatorname{clim} 1$ and $\operatorname{clim} 2=$ composite climate axes from PCA of precipitation and temperature variables (see Figure S2). 